\title{
Research Square \\ New Strategies for Early Diagnosis and Treatment of Osteoid Osteoma of the Lesser Trochanter of Femur
}

\section{Xinzhu Qiu}

Xiangya Hospital Central South University

Hongbo He

Xiangya Hospital Central South University

Hao Zeng

Xiangya Hospital Central South University

Xiaopeng Tong

Xiangya Hospital Central South University

Qing Liu ( $\nabla 158112225 @ c s u . e d u . c n)$

Xiangya Hospital Central South University

\section{Research Article}

Keywords: Osteoid osteoma, proximal femoral, open surgery, misdiagnosis, thin-layer CT

Posted Date: September 30th, 2021

DOI: https://doi.org/10.21203/rs.3.rs-919658/v1

License: (c) (i) This work is licensed under a Creative Commons Attribution 4.0 International License. Read Full License 


\section{Abstract}

Aims: Herein, we examined the efficacy of open resection in proximal femoral osteoid osteoma (OO) treatment. Besides, we analysed the causes of misdiagnosis of proximal femoral 00 to provide a reference for its diagnosis and treatment.

Methods: This was a retrospective study involving 29 patients with proximal femoral 00 admitted into our hospital from January 2010 to January 2018. The baseline characteristics of the participants included; 21 males and 9 females, aged between 13 to 25 (mean 16.2) years old, and the course of the disease was 1 to 14 (mean 6.1) months. We used previous medical experience records of the patients to analyze for the causes of misdiagnosis. Moreover, we compared the difference between preoperative and postoperative treatment practices in alleviating pain in 00 patients and restoring hip function. Follow-ups were conducted regularly, and patients advised to avoid strenuous exercises for 3 months.

Results: We followed up 29 patients (21 intercortical, 2 sub-periosteal, and 6 medullary) for an average of 42.5 months. We found that 13 patients $(44.8 \%)$ had been misdiagnosed of synovitis, Perthes disease, osteomyelitis, intra-articular infection, and joint tuberculosis, whose average time from symptoms to diagnosis were 9.8 months. Postoperative pain score and joint function score improved significantly compared with preoperative, and complications were rare.

Conclusion: Open surgical resection constitutes an effective treatment for proximal femoral 00 by accurately and completely removing the nidus. Lack of understanding, wrong choice of examination, and the complexity and diversity of clinical manifestations constitute the main reasons for the misdiagnosis of proximal femoral 00 .

\section{Highlights}

1. Lack of understanding, wrong choice of examination, and the complexity and diversity of clinical manifestations constitute the main reasons for the misdiagnosis of proximal femoral osteoid osteoma.

2. Thin slice CT is superior to MRI in the diagnosis of osteoid osteoma, which should be the first choice in the diagnosis of osteoid osteoma.

3. Open surgical resection constitutes an effective treatment for proximal femoral $\mathrm{OO}$ by accurately and completely removing the nidus.

\section{Introduction}

Osteoid osteoma (OO) constitutes a benign osteogenic tumour typified by persistent blunt pain with nocturnal aggravation that is relieved by oral nonsteroidal anti-inflammatory drugs[1-3]. 00 is characterized by a round nidus of tumour tissue with a diameter of less than $2 \mathrm{~cm}$, mostly less than $1 \mathrm{~cm}$, and the lesion is composed of bone-like tissue, rich in blood vessels, and cells[1]. The morbidity of 00 
accounts for about $10 \%$ of benign bone tumors, which accounts for $2-3 \%$ of all primary bone tumors. 00 most frequently affects individuals in their second and third decades of life with significantly higher morbidity in males compared to females, and the ratio ranges between 2:1 and 3:1 [3,4]. It predominantly occurs in the cortex of the long tubular bone, particularly in the femur and tibia, with the proximal femoral more frequently involved. $\mathrm{OO}$ is categorized into sub-periosteal, intra-cortical, and medullary based on the position of the nidus within the bone (Fig. 1). Intra-cortical 00 is the most common, representing approximately $75 \%$ of the lesions. On the contrary, medullary 00 is relatively rare and typically juxtaarticular in location, its less reactive bone around the nidus complicates diagnosis[3, 5].

The $\mathrm{OO}$ of the proximal femur is adjacent to the hip joint, and the complex structure of the hip joint makes it susceptible to multiple bone and soft tissue tumours[4, 6-9]. Therefore, 00 occurring at the hip joint presents with atypical clinical symptoms and imaging manifestations, so it is easy to be misdiagnosed or missed, and patients often suffer unnecessary treatment due to delayed diagnosis, resulting in great physical suffering and financial burden[10-12]. There are still some controversies over the treatment of proximal femoral 00 considering the particular location of the nidus. Open surgical resection and minimally invasive radiofrequency ablation also have their own advantages[13-18]. Therefore, this study introduces our bone tumor center's experience in the diagnosis and treatment of 00 of the proximal femur in detail, and defines the potential pitfalls in the diagnosis and treatment process, so as to realize the rapid and accurate diagnosis and optimize the treatment strategy of 00 of the proximal femur.

\section{Materials And Methods}

\subsection{Patients}

According to the approval of the ethics committee of Xiangya Hospital, follow-up analysis was performed on the patients with 00 treated in our hospital, and the data of 84 consecutive patients admitted in our hospital from January 2010 to January 2018 were analyzed. The inclusion criteria constituted; pathological confirmation of $\mathrm{OO}$, location of the nidus in the proximal femoral, open surgical resection was used in the treatment, complete follow-up data with a follow-up time of more than 24 months. The exclusion criteria composed; 00 patients receiving other surgical treatments other than open surgical resection, less than 24 months of follow-up or incomplete follow-up data. All patients participating in the study received informed consent and signed consent from the patient or their legal guardians.

\subsection{Preoperative diagnosis and evaluation}

Pain is almost the only symptom in the early stage of 00 . The pain is fixed and persistent, more pronounced at night, and is usually relieved by oral use of non-steroidal anti-inflammatory drugs (NSAIDs). Severe symptoms cause lameness and atrophy of limb muscles. Typical radiography characteristics of $\mathrm{OO}$ include fusiform sclerosis of the cortex centered on the nidus, which is a transparent area with a diameter of less than $2 \mathrm{~cm}$ (Fig. 2a). Computed tomography (CT) constitutes the most valuable 00 diagnosis approach, which more accurately shows the nidus and the osteosclerotic 
area. Typical patients present with the bull's eye sign caused by the calcification of the focus center (Fig. 2b). Because of the lack of characteristic signal and the relatively low spatial resolution of magnetic resonance imaging (MRI), which is inferior in the diagnosis of 00 compared with $\mathrm{CT}$. Therefore, all patients underwent radiography and CT examinations before the operation, and some patients underwent MRI (Fig. 2c).

Demographic and clinical information was recorded before all procedures, including symptoms, time from symptoms to diagnosis, physical examination, misdiagnosis, and imaging findings. NSAIDs treatment was given to all patients before operation, and a visual analogue scale (VAS) [19] was used to evaluate pain pre and post-treatment. We used the modified Harris score system to evaluate hip joint function [20].

\subsection{Procedure}

Considering that the 00 of the proximal femur was mostly located in the femoral neck or lesser trochanter, and some cases were located in the joint capsule, so we choose Simth-Petersen (SP) approach for lesion resection. Enter along the gap between tensor fascia lata and sartorius muscle, pay attention to protect the lateral femoral cutaneous nerve, after exposing rectus femoris and gluteus medius muscle, ligate the ascending branch of external circumflex femoral artery, then pull the rectus femoris to the inside and gluteus medius muscle to the outside to expose the joint capsule. Using C-arm machine to locate the lesion, then adduction and full external rotation of the lower limbs to expose the lesion. We used $\mathrm{T}$ type incision of the articular capsule for intra-articular lesions. A high-speed burr was used to remove the hyperplastic reaction bone on the surface, curettage the pathological tissue with a curette and carry out pathological examination. Subsequently, the high-speed burr was used to expand the curettage boundary, after thorough washing of the surgical field, the electric knife was used to burn the periphery of the nidus to ensure the thorough removal of the lesions. Bone grafting were performed for lesions with a large range of bone defects, and then the incision was sutured successively and drainage tube was placed.

\subsection{Follow-up and evaluation}

We intravenously administered antibiotics until the drainage tube was removed to encourage early postoperative activity. The patients used crutches for walking within 1 month and avoided strenuous exercise within 3 months after the operation. Patients were followed-up radiographically every 3 months for the first 2 years, every 6 months until the 5th year, and annually after that. The follow-up involved the evaluation of postoperative pain, joint function, and recording the occurrence of complications.

\subsection{Statistical Analysis}

SPSS 20.0 (SPSS Inc., IBM, Chicago) statistical software was used in data analysis. The quantitative data were expressed by mean \pm standard deviation. Preoperative and postoperative VAS pain scores and modified Harris scores were analyzed using the paired T-test. $P$ value $\leq 0.05$ indicated statistical significance. 


\section{Results}

\subsection{Demographic and clinical record}

We enrolled 29 patients into this study, with an average age of $16.2 \pm 3.5$ years (13-25 years), comprising of 20 males and 9 females (supplemental table). The radiography results of 23 cases revealed an increase in local density and different degrees of cortical thickening, and 13 cases had low-density nidus. Thin-slice CT scans revealed nidus across all the patients, in which 21 were intra-cortical, 6 medullary, and 2 sub-periosteal. Fifteen patients with calcification in the lesion had the bull's eye sign changes. The first symptoms reported by patients included hip pain with evident nocturnal pain. The VAS scores were $5.8 \pm 1.0(4-7)$ in preoperative un-administered NSAIDs status and 0 after NSAIDs administration. The average duration in this group was $6.1 \pm 3.8$ months (1-14 months), 9 patients had lameness preoperative, three patients had atrophy of limb muscles, and the average Harris score of hip joint preoperative was $53.7 \pm 10.4$ points (34-77) (Table 1 ). 
Table 1

Demographic and clinical information of patients

\begin{tabular}{|c|c|c|c|}
\hline \multicolumn{4}{|l|}{ Gender } \\
\hline \multicolumn{2}{|l|}{$M$} & \multicolumn{2}{|l|}{$20(69.0 \%)$} \\
\hline \multicolumn{2}{|l|}{$F$} & \multicolumn{2}{|l|}{$9(31.0 \%)$} \\
\hline \multicolumn{2}{|l|}{ Age(years) } & \multicolumn{2}{|l|}{$16.2 \pm 3.5$} \\
\hline \multicolumn{4}{|l|}{ Classification } \\
\hline \multicolumn{2}{|l|}{ subperiosteal } & \multicolumn{2}{|l|}{$2(6.9 \%)$} \\
\hline \multicolumn{2}{|l|}{ intracortical } & \multicolumn{2}{|l|}{$21(72.4 \%)$} \\
\hline \multicolumn{2}{|l|}{ medullary } & \multicolumn{2}{|l|}{$6(20.7 \%)$} \\
\hline \multicolumn{4}{|l|}{ Localization } \\
\hline \multicolumn{2}{|l|}{ intra-articular } & \multicolumn{2}{|l|}{$12(41.4 \%)$} \\
\hline \multicolumn{2}{|l|}{ extra-articular } & \multicolumn{2}{|l|}{$17(58.6 \%)$} \\
\hline \multicolumn{2}{|c|}{ Duration of symptom (months) } & \multicolumn{2}{|l|}{$6.1 \pm 3.8$} \\
\hline \multicolumn{4}{|l|}{ Misdiagnosis } \\
\hline \multicolumn{2}{|l|}{ synovitis } & \multicolumn{2}{|l|}{$2(6.9 \%)$} \\
\hline \multicolumn{2}{|c|}{ perthes disease } & \multicolumn{2}{|l|}{$1(3.4 \%)$} \\
\hline \multicolumn{2}{|l|}{ osteomyelitis } & \multicolumn{2}{|l|}{$7(24.1 \%)$} \\
\hline \multicolumn{2}{|c|}{ intra-articular infection } & \multicolumn{2}{|l|}{$2(6.9 \%)$} \\
\hline \multicolumn{2}{|c|}{ joint tuberculosis } & \multicolumn{2}{|l|}{$1(3.4 \%)$} \\
\hline \multicolumn{2}{|c|}{ Follow-up time(months) } & \multicolumn{2}{|l|}{$42.5 \pm 15.4$} \\
\hline $\begin{array}{l}\text { Comparative } \\
\text { analysis }\end{array}$ & Preoperative & Postoperative & $P$ value \\
\hline VAS score & $5.8 \pm 1.0$ & 0 & $P<0.01$ \\
\hline Harris score & $53.7 \pm 10.4$ & $99.4 \pm 1.0$ & $P<0.01$ \\
\hline
\end{tabular}

\subsection{Misdiagnosis}

In this group, 18 cases were initially diagnosed in other hospitals, in which 13 were misdiagnosed (misdiagnosis rate, $72.2 \%$ ). Six patients visited two hospitals, with 2 having visited more than three hospitals. The duration of symptoms from the onset to diagnosis was $9.8 \pm 2.0$ months. Misdiagnosis of 
synovitis and intra-articular infection were reported in two cases each, Perthes disease and joint tuberculosis in one case each, and osteomyelitis in seven cases. Twenty-four patients (82.8\%) had taken NSAIDs, two patients (6.9\%) had taken hormone and immunosuppressive drugs, one patient (3.4\%) had received anti-tuberculosis treatment, nine patients $(31.0 \%)$ had received surgical treatment, seven patients (24.1\%) had acupuncture and physical therapy in traditional Chinese medicine (TCM).

\subsection{Follow up and evaluation}

The average follow-up time was $42.5 \pm 15.4$ months (24-81 months). The initial pain symptoms of the patient disappeared within one week after surgery. The properties of postoperative pain are different from those of preoperative pain; therefore, NSAIDs are not administered. VVAS score was 0 at the first followup, and there no recurrence of pain was reported henceforth. The average Harris score of the hip joint postoperative was $99.4 \pm 1.0$ (97-100). During the follow-up, no complications, including infections, fractures, deep vein thrombosis, and ischemic necrosis of the femoral head, occurred. Besides, no manifestation of femoral nerve injuries such as superficial paresthesia and decreased muscle strength was observed. Postoperative radiography examination showed that there was no recurrence of lesions, the original reactive hyperplastic bone was self-absorbed, and the morphology of the femur was restored to normal (Fig. 3).

\section{Discussion}

$\mathrm{OO}$ is a benign bone tumour with pain as the first symptom accompanied by evident nocturnal pain and typical intra-cortical nidus surrounded by sclerosis and cortical thickening as the primary manifestation, which often requires surgical intervention[3, 6, 21-23]. The proximal femoral constitutes the most susceptible part for 00 , which is challenging to treat because of its deep location, close to the hip joint, and complex local anatomy $[4,14,15,17,24]$. Presently, the main surgical treatment methods for 00 include open surgical resection and minimally invasive treatment, such as CT guided radiofrequency ablation (RFA) [25-28], cryoablation[17], and microwave ablation[29]. Whatever the kind of treatment adopted, the key to successful surgical treatment of 00 is based on the accurate location of the nidus and its subsequent complete removal[3-6]. Minimally invasive surgery has the advantages of less trauma, precise location, and short operation time. However, it requires high hardware conditions, high technical operation requirements, presents with incomplete removal of the nidus, easy to damage adjacent tissues, and unable to carry out a pathological examination, and among other limitations, which affect its popularization and application[8, 17, 25, 30-32]. At the same time, minimally invasive surgery is significantly inferior to open surgical resection in terms of 00 recurrence rate and incidence of complications $[25,29,33,34]$. The trauma associated with open surgery is relatively higher but wholly and accurately results in the removal of the nidus, improving the positive rate of pathological examination, and reduces the postoperative recurrence rate. Synovium cleaning and local soft tissue loosening are conducted where necessary, and bone grafting is performed for large bone defects, to reduce the risk of postoperative fractures. Given that the proximal femoral is close to the hip joint, the local anatomical 
structure is complex, and it is close to the important neurovascular femoral nerve, we speculated that open surgical resection is more suitable for the treatment of proximal femoral 00.

In the cohort, 29 patients were treated using open surgical resection and SP approach was selected aid in exposing the foci. This surgical approach completely avoids the anterior femoral arteriovenous and femoral nerves, and fully exposes the lesion of the proximal femoral without affecting blood supply to the femoral head, so as to clear the nidus under direct vision. During the follow-up period, none of the patients in this group had recurrence postoperatively, nor signs of femoral nerve injury such as decreased muscle strength. Additionally, deep vein thrombosis and femoral head necrosis were not observed. Postoperative VAS score and modified Harris score were significantly improved compared with preoperative.

The healing effect of open surgical resection on 00 is highly effective, but the diagnosis of 00 at proximal femoral is challenging; hence requires further investigations. In our study, the preoperative misdiagnosis rate was $44.8 \%$, and a significant number of the patients underwent multiple surgical procedures due to misdiagnosis. This causes considerable physical suffering and financial burden. Through comparative analysis, we found that the complex and diverse clinical manifestations of proximal femoral 00 cause its objective misdiagnosis, whereas lack of clear understanding of the disease and selection of the wrong method of examination constitute the frequent subjective causes of misdiagnosis[6, 25, 34-36]. 00 is characterized by persistent pain, accompanied by nocturnal pain, which is relieved by oral use of NSAIDs. However, $\mathrm{OO}$ in the proximal femoral is associated with joint cavity effusion, bone marrow edema, and soft tissue swelling. These nonspecific inflammatory reactions increase the pressure in the joint cavity, leading to changes in the property of the pain. Furthermore, considering that the first visit of most patients to the doctor comprise of non-osteooncologists, even with typical clinical manifestations, proximal femoral 00 is easily ignored. The tiny nidus in the early stage and the inconspicuous surrounding osteosclerosis make inexperienced radiologists overlook the possibility of 00 , which additionally results in misdiagnosis or missed diagnosis. At the same time, MRI is widely used as the preferred method of examining joints as patients mostly present with hip joint pain. The tiny nidus lacks characteristic signals, and the spatial resolution of MRI is relatively low in addition to being sensitive to joint swelling[11, 14, 15, 37], fluid accumulation, and bone marrow abnormalities, which easily attract the radiology reader's attention affecting the diagnosis. On the contrary, thin-layer CT has an optimal spatial resolution, accurately displaying the nidus and abnormal calcifications, especially for sites with complex anatomical structures. Therefore, thin-layer CT constitutes the most valuable method for the diagnosis of 00 .

The clinical and imaging manifestations of proximal femoral 00 are not necessarily representative. There could be significant differences in the performance of patients during different periods. Therefore, proximal femoral 00 should be clearly distinguished from the following diseases at the diagnosis $[1-3,5$, $10-12,38]$ : $\otimes$ Sclerosing osteomyelitis whose radiography manifestations include symmetric thickening and sclerosis of the bilateral bone cortex with no nidus transparent area. The pain is intermittent with no nocturnal pain, and salicylic acid is ineffective. $\otimes$ Osteoblastoma, which is located in a cancellous bone, 
which is very similar to 00 in histology. The lesion is more than $2 \mathrm{~cm}$ in a cystic translucent area, with extensive destruction of the bone, swelling of bone cortex, and calcification or ossification in the lesions. $\nabla$ Chronic localized bone abscess disease that is prone to the epiphysis of the long diaphysis, with evident inflammatory manifestations, including redness, swelling, heat, pain, and a history of repeated attacks, without the regular pain of 00 . $\otimes$ Synovitis of the hip joint, which often occurs in young children, and the symptoms are transient. The course of disease rarely exceeds three weeks. There is a history of violent activity before the onset, and the pain symptoms are quickly relieved after motionless rest. $₫$ Synovial tuberculosis of the hip typified by systemic tuberculosis poisoning with the radiography showing widening of the hip joint space. 『Perthes disease characterized by hip pain and lameness as the primary symptoms, the femoral head presents with a crescent sign, and the necrosis of the femoral head may collapse.

Although the results of this study are satisfactory, there are still the following limitations. The small sample size poses a challenge of establishing the potential links between demographic, imaging or clinical features, and treatment failure or complications. Secondly, the specific efficacy of this operation in the treatment of proximal femoral $\mathrm{OO}$ has no case-control and effective comparative analysis. Therefore, further studies should be conducted using a large sample with a multicentre case-control study.

In summary, open surgical resection constitutes an effective method for the treatment of proximal femoral 00. Accurate and complete removal of the nidus is the core concept of this surgical treatment. Lack of clear understanding of the disease, wrong selection of examination methods, and the complexity and diversity of its clinical manifestations constitute the primary reasons for the misdiagnosis of proximal femoral 00.

\section{Abbreviations}

OO, osteoid osteoma; NSAIDs, non-steroidal anti-inflammatory drugs; CT, computed tomography; MRI, magnetic resonance imaging; VAS, visual analogue scale; SP, simth-petersen; RFA, radiofrequency ablation.

\section{Declarations}

\section{Author contributions}

$\mathrm{HH}$ and QL designed the study. QL, XQ, HZ and XT collected clinical data. $\mathrm{HZ}$ and $\mathrm{XT}$ analyzed the data. $\mathrm{QL}$ and $\mathrm{XQ}$ wrote the manuscript. QL reviewed the manuscript. All the authors agreed to the publication of the study.

\section{Ethical review committee statement}


This study was performed in compliance with the ethical principles of the Declaration of Helsinki and Good Clinical Practices, this study has been approved by the Ethics Committee of Xiangya Hospital.

\section{Acknowledgements}

We would like to give our sincere thanks to Dr. Wei Luo, Dr. Can Zhang, Dr. Zhan liao and Dr. Yupeng Liu for assistance in data collection.

\section{Disclosure}

The authors declared no potential conflicts of interest with respect to the research, authorship, and/or publication of this article. No benefits in any form have been received or will be received from a commercial party related directly or indirectly to the subject of this article. The patients and their families were invited to participate and provided informed consent upon learning of the study's risks and benefits.

\section{Availability of data and materials}

All the data used in the article can be obtained from the medical record information system of Xiangya Hospital, Central South University. Any questions or enquiries regarding the present study can be directed to Qing Liu, MD, PhD (158112225@csu.edu.cn), as corresponding author.

\section{Funding}

This work was supported by the Hunan Youth Science and Technology Innovation Talent Project (2020RC3058), the Research project of Hunan health and Family Planning Commission (C20180785).

\section{Conflict of interests}

The authors declared no potential conflicts of interest with respect to the research, authorship and/or publication of this article.

\section{References}

1. Matthies L, Rolvien T, Pakusa TJ, Knipfer C, Gosau M, Amling M, Friedrich RE, Zustin J. Osteoid Osteoma of the Mandible - Clinical and Histological Findings. Anticancer Res. 2018; 39(1):291-296.

2. Laurence N, Epelman M, Markowitz RI, Jaimes C, Jaramillo D, Chauvin NA. Osteoid osteomas: a pain in the night diagnosis. Pediatr Radiol. 2012; 42(12):1490-1501, 1540-1542.

3. Hakim DN, Pelly T, Kulendran M, Caris JA. Benign tumours of the bone: A review. J Bone Oncol. 2015; 4(2):37-41.

4. May CJ, Bixby SD, Anderson ME, Kim YJ, Yen YM, Millis MB, Heyworth BE. Osteoid Osteoma About the Hip in Children and Adolescents. J Bone Joint Surg Am. 2019; 101(6):486-493.

5. Lee EH, Shafi M, Hui JH. Osteoid osteoma: a current review. J Pediatr Orthop. 2006; 26(5):695-700. 
6. Rolvien T, Krause M, Zustin J, Yastrebov O, Oheim R, Barvencik F, Frosch KH, Amling M. Intra-articular osteoid osteoma accompanied by extensive bone marrow edema. A clinical and micromorphological analysis. J Bone Oncol. 2019; 18:100256.

7. Gao K, Hua Y, Chen S, Li Y, Xin Q. Arthroscopic excision of juxtaarticular cancellous osteoid osteoma in the talar neck. Knee Surg Sports Traumatol Arthrosc. 2013; 21(6):1300-1303.

8. Gangi A, Alizadeh H, Wong L, Buy X, Dietemann JL, Roy C. Osteoid osteoma: percutaneous laser ablation and follow-up in 114 patients. Radiology. 2007; 242(1):293-301.

9. Liu Q, He H, Zeng H, Yuan Y, Long F, Tian J, Luo W. Modified trapdoor procedures by surgical dislocation approach to treat chondroblastoma of the femoral head. The Bone \& Joint Journal. 2019; 101-B(6):732-738.

10. Franceschi F, Marinozzi A, Papalia R, Longo UG, Gualdi G, Denaro E. Intra- and juxta-articular osteoid osteoma: a diagnostic challenge: misdiagnosis and successful treatment: a report of four cases. Arch Orthop Trauma Surg. 2006; 126(10):660-667.

11. Scalici J, Jacquel A, Mukish P, Trouilloud P, Baulot E. Intra-articular osteoid osteoma of the hip misdiagnosed by MRI: an unusual cause of unexplained hip pain. Orthop Traumatol Surg Res. 2011; 97(8):881-885.

12. Dubuc JE, Docquier PL, Schubert T, Galant C, Malghem J. Diagnosis failure led to the recurrence of an intra-articular osteoid osteoma at the talus neck after arthroscopic excision. Foot Ankle Surg. 2014; 20(3):e40-e42.

13. Niazi GE, Basha M, Elsharkawi W, Zaitoun M. Computed Tomography-Guided Radiofrequency Ablation of Osteoid Osteoma in Atypical Sites: Efficacy and Safety in a Large Case Series. Acad Radiol. 2020.

14. Chai JW, Hong SH, Choi J, Koh YH, Lee JW, Choi J, Kang HS. Radiologic Diagnosis of Osteoid Osteoma: From Simple to Challenging Findings. Radiographics. 2010; 30(3):737-749.

15. Gaeta M, Minutoli F, Pandolfo I, Vinci S, D Andrea L, Blandino A. Magnetic resonance imaging findings of osteoid osteoma of the proximal femur. Eur Radiol. 2004; 14(9):1582-1589.

16. Vidoni A, Grainger M, James S. Experience of neuroprotective air injection during radiofrequency ablation (RFA) of spinal osteoid osteoma. Eur Radiol. 2018; 28(10):4146-4150.

17. Santiago E, Pauly V, Brun G, Guenoun D, Champsaur P, Le Corroller T. Percutaneous cryoablation for the treatment of osteoid osteoma in the adult population. Eur Radiol. 2018; 28(6):2336-2344.

18. Napoli A, Bazzocchi A, Scipione R, Anzidei M, Saba L, Ghanouni P, Cozzi DA, Catalano C. Noninvasive Therapy for Osteoid Osteoma: A Prospective Developmental Study with MR Imaging-guided HighIntensity Focused Ultrasound. Radiology. 2017; 285(1):186-196.

19. Mizuno M, Fukunaga A, Washio K, Imamura S, Oda Y, Nishigori C. A visual analogue scale for itch and pain in 23 cases of cholinergic urticaria. J Eur Acad Dermatol Venereol. 2020.

20. Edwards PK, Queen RM, Butler RJ, Bolognesi MP, Lowry BC. Are Range of Motion Measurements Needed When Calculating the Harris Hip Score? J Arthroplasty. 2016; 31(4):815-819. 
21. Esteban Cuesta H, Martel Villagran J, Bueno Horcajadas A, Kassarjian A, Rodriguez Caravaca G. Percutaneous radiofrequency ablation in osteoid osteoma: Tips and tricks in special scenarios. Eur $\mathrm{J}$ Radiol. 2018; 102:169-175.

22. Kayser F, Resnick D, Haghighi P, Pereira ER, Greenway G, Schweitzer M, Kindynis P. Evidence of the subperiosteal origin of osteoid osteomas in tubular bones: analysis by CT and MR imaging. AJR Am J Roentgenol. 1998; 170(3):609-614.

23. Raux S, Abelin-Genevois K, Canterino I, Chotel F, Kohler R. Osteoid osteoma of the proximal femur: treatment by percutaneous bone resection and drilling (PBRD). A report of 44 cases. Orthop Traumatol Surg Res. 2014; 100(6):641-645.

24. Guo X, Li X, Li Z, Peng D, Zhang X, Zhang Q. [Therapeutic effect analysis for open resection in osteoid osteoma around lesser trochanter of femur]. Zhong Nan Da Xue Xue Bao Yi Xue Ban. 2016; 41(12):1291-1296.

25. Oc Y, Kilinc BE, Cennet S, Boyacioglu MM, Ertugrul R, Varol A. Complications of Computer Tomography Assisted Radiofrequency Ablation in the Treatment of Osteoid Osteoma. Biomed Res Int. 2019; 2019:4376851.

26. Niazi GE, Basha MAA, Elsharkawi WFA, Zaitoun MMA. Computed Tomography-Guided Radiofrequency Ablation of Osteoid Osteoma in Atypical Sites: Efficacy and Safety in a Large Case Series. Acad Radiol. 2020.

27. Paladini A, Lucatelli P, Cappelli F, Pizzi G, Anelli V, Amodeo EM, Beomonte ZD, Paladini L, Biagini R, Attala $\mathrm{D}$, et al. Osteoid osteoma treated with radiofrequency ablation in non-operating room anesthesia. A different way of approaching ablative therapy on osteoid osteoma. Eur Rev Med Pharmacol Sci. 2018; 22(17):5438-5446.

28. Cioni R, Armillotta N, Bargellini I, Zampa V, Cappelli C, Vagli P, Boni G, Marchetti S, Consoli V, Bartolozzi C. CT-guided radiofrequency ablation of osteoid osteoma: long-term results. Eur Radiol. $2004 ; 14(7)$.

29. Rinzler ES, Shivaram GM, Shaw DW, Monroe EJ, Koo KSH. Microwave ablation of osteoid osteoma: initial experience and efficacy. Pediatr Radiol. 2019; 49(4):566-570.

30. Napoli A, Mastantuono M, Cavallo MB, Anzidei M, Zaccagna F, Moreschini O, Passariello R, Catalano C. Osteoid osteoma: MR-guided focused ultrasound for entirely noninvasive treatment. Radiology. 2013; 267(2):514-521.

31. Bousson V, Leturcq T, Ea H, Hauger O, Mehsen-Cetre N, Hamzé B, Parlier-Cuau C, Laredo J, Schaeverbeke T, Orcel P. An open-label, prospective, observational study of the efficacy of bisphosphonate therapy for painful osteoid osteoma. Eur Radiol. 2018; 28(2):478-486.

32. Georgoulis AD, Papageorgiou CD, Moebius UG, Rossis J, Papadonikolakis A, Soucacos PN. The diagnostic dilemma created by osteoid osteoma that presents as knee pain. Arthroscopy: The Journal of Arthroscopic \& Related Surgery. 2002; 18(1):32-37.

33. Shields DW, Sohrabi S, Crane EO, Nicholas C, Mahendra A. Radiofrequency ablation for osteoid osteoma - Recurrence rates and predictive factors. The Surgeon. 2018; 16(3):156-162. 
34. Hage AN, Chick J, Gemmete JJ, Grove JJ, Srinivasa RN. Percutaneous Radiofrequency Ablation for the Treatment of Osteoid Osteoma in Children and Adults: A Comparative Analysis in 92 Patients. Cardiovasc Intervent Radiol. 2018; 41(9):1384-1390.

35. Spiker AM, Rotter BZ, Chang B, Mintz DN, Kelly BT. Clinical presentation of intra-articular osteoid osteoma of the hip and preliminary outcomes after arthroscopic resection: a case series. J Hip Preserv Surg. 2018; 5(1):88-99.

36. Sharma KV, Yarmolenko PS, Celik H, Eranki A, Partanen A, Smitthimedhin A, Kim A, Oetgen M, Santos D, Patel J, et al. Comparison of Noninvasive High-Intensity Focused Ultrasound with Radiofrequency Ablation of Osteoid Osteoma. J Pediatr. 2017; 190:222-228.

37. Bhure U, Roos JE, Strobel K. Osteoid osteoma: multimodality imaging with focus on hybrid imaging. Eur J Nucl Med Mol Imaging. 2019; 46(4):1019-1036.

38. Erdogan O, Gurkan V. Hand osteoid osteoma: evaluation of diagnosis and treatment. Eur J Med Res. 2019; 24(1):3.

\section{Figures}


subperiosteal
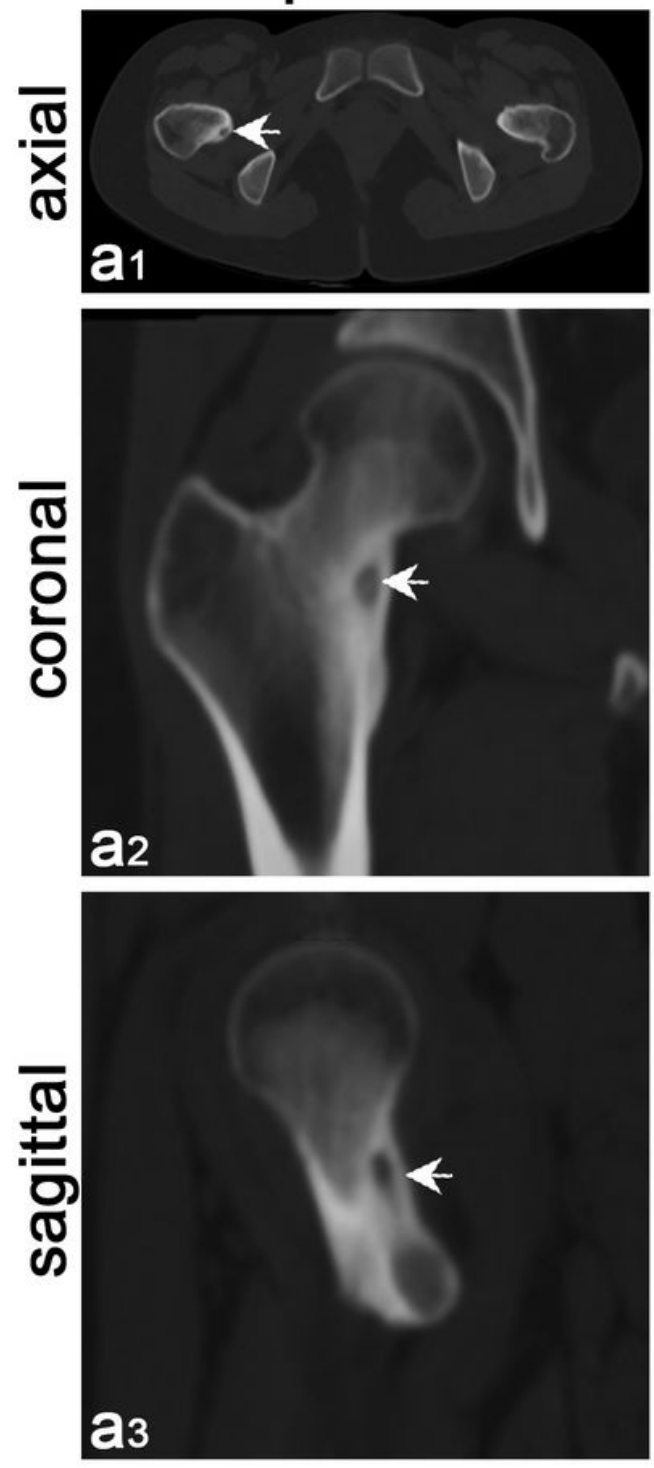

intracortical
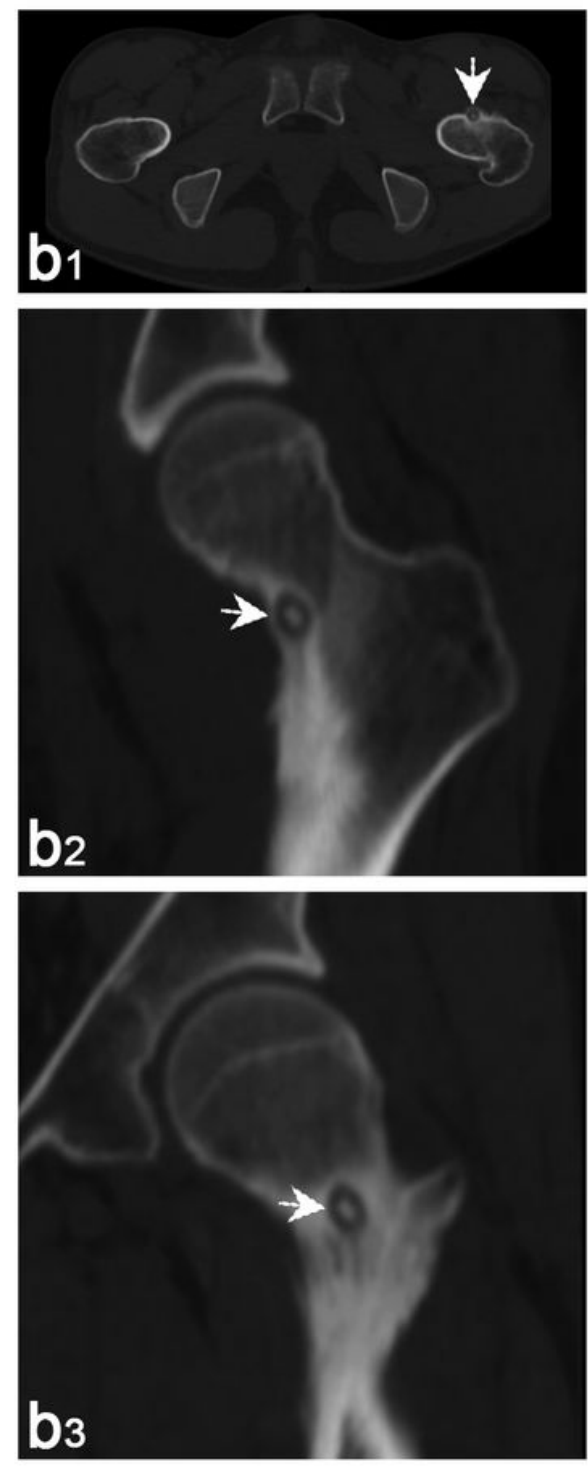

medullary

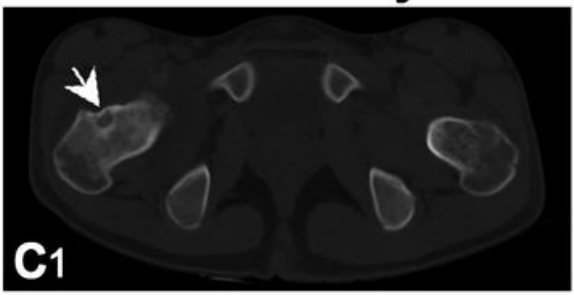

$\mathbf{C}_{2}$

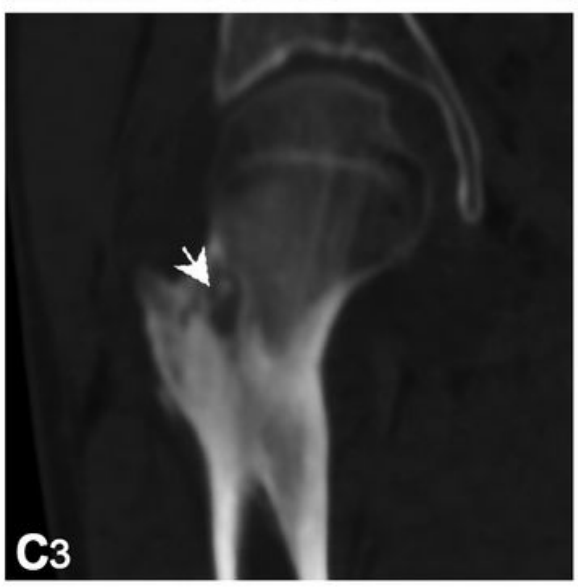

Figure 1

00 was classified into sub-periosteal, intra-cortical, and medullary type based on the location of the nidus using thin-layer CT. (a1-a3) Sub-periosteal: the nidus is located under the periosteum and outside the cortex; (b1-b3) intra-cortical: the nidus is located inside the bone cortex and expands inwards and outwards; (c1-c3) medullary: the nidus is completely intramedullary. The white arrow shows the nidus, some of which have high-density calcification. 

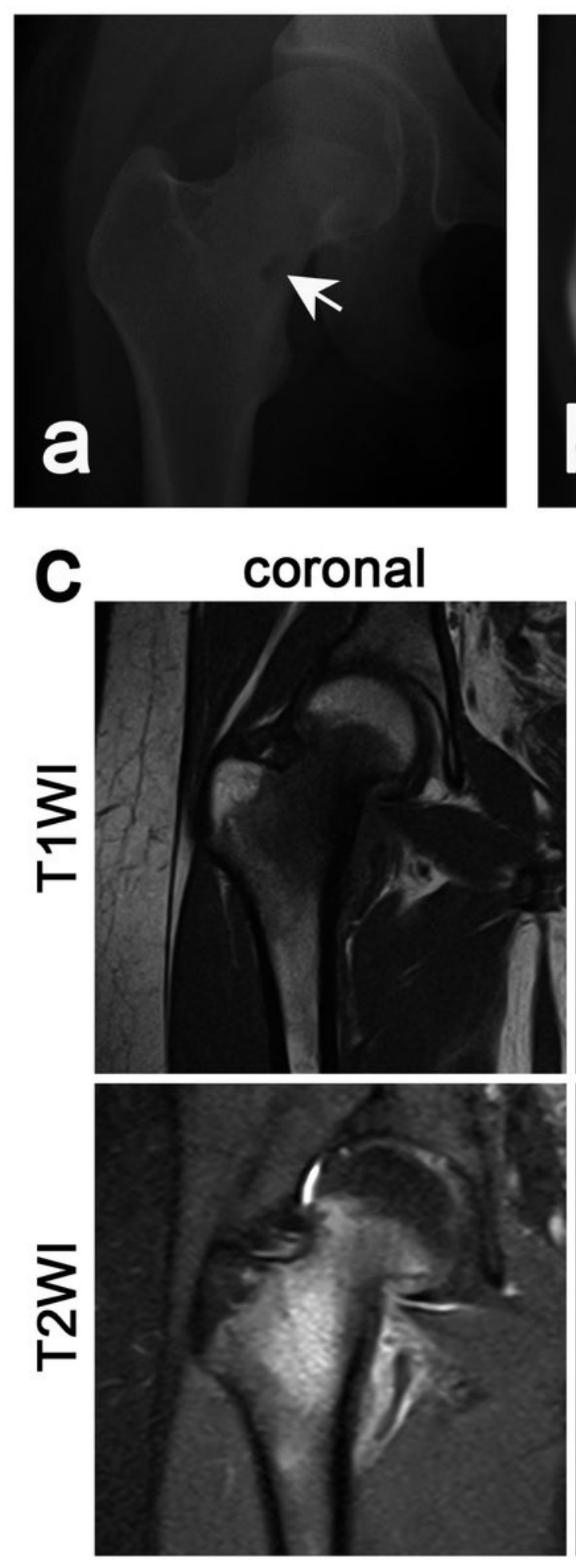

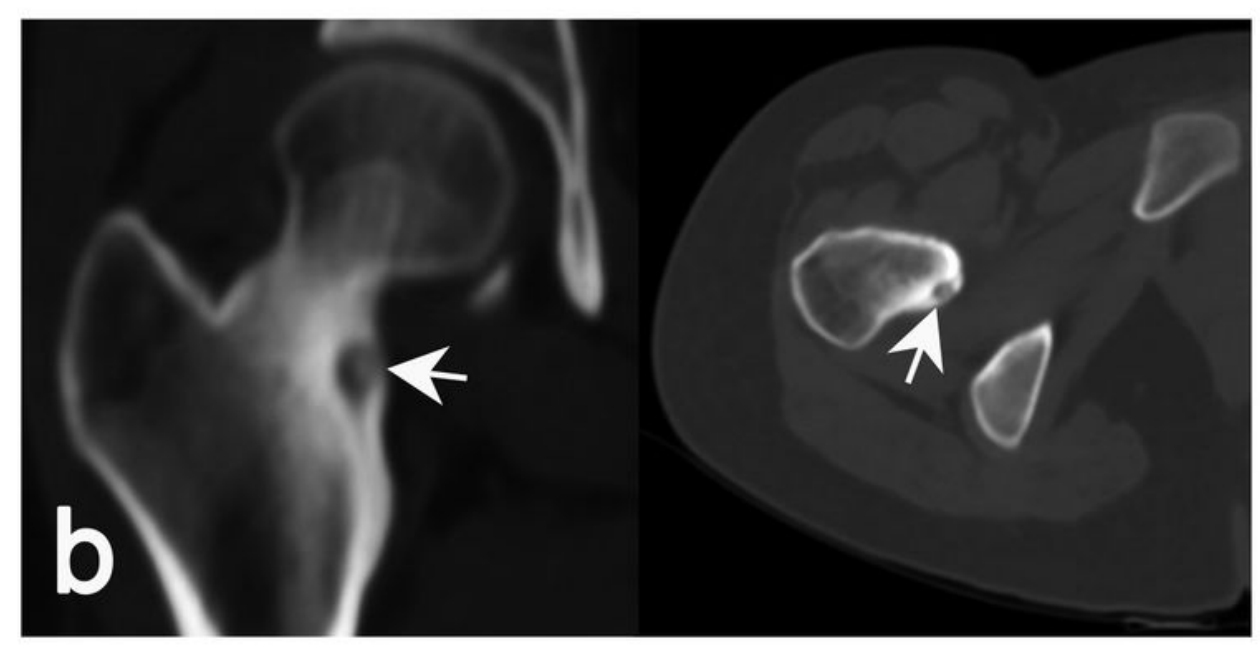

axial
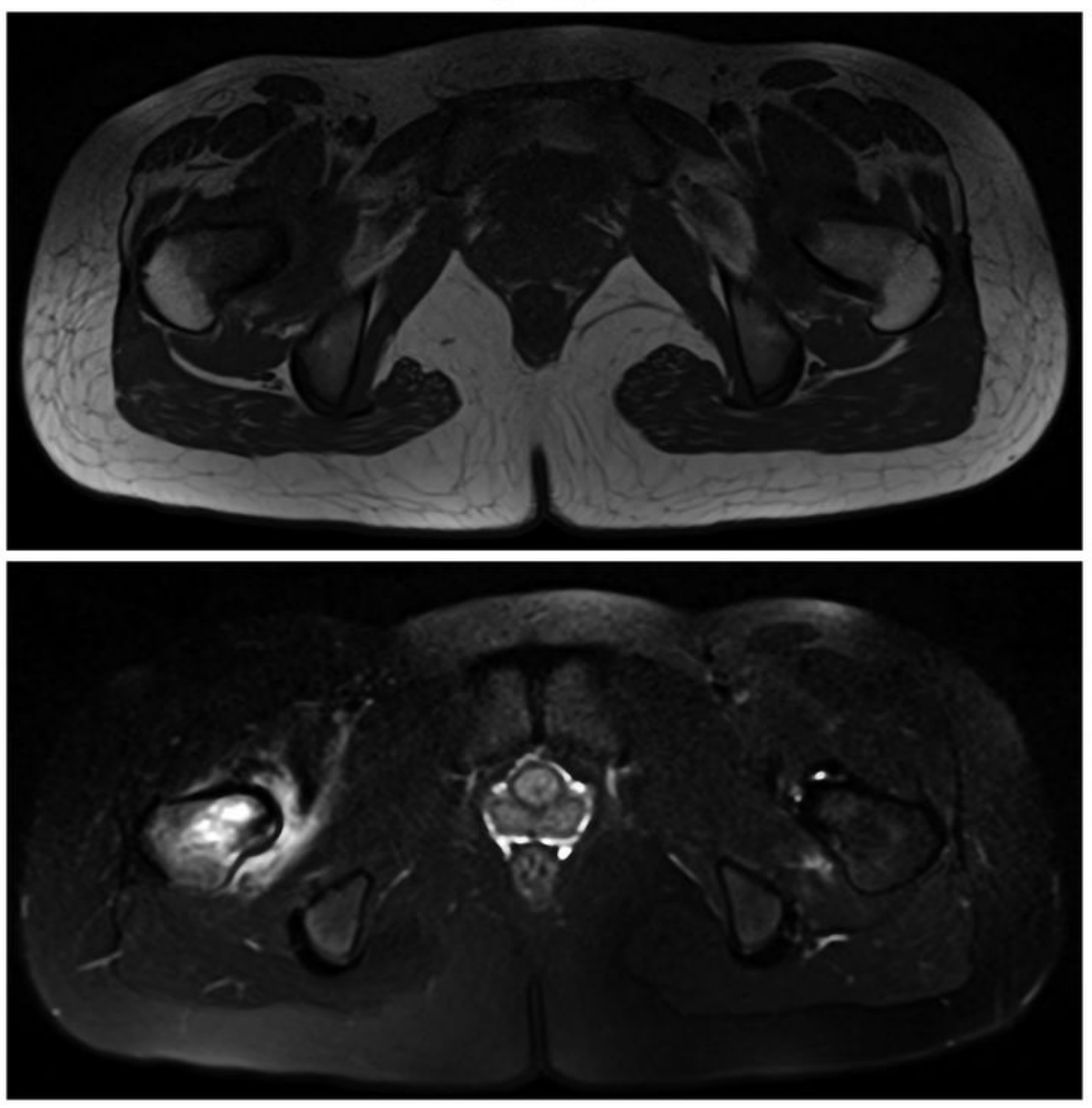

Figure 2

Imaging examination significantly helped in the diagnosis of OO. (a) The radiography examination shows a round and transparent area. (b) Thin-layer CT accurately displays the nidus and the surrounding reactive hyperplastic bone tissue (the white arrow shows the nidus). (c) MRI examination lacks specificity, T1WI shows low to moderate signal intensity and T2WI shows moderate to high signal intensity. 

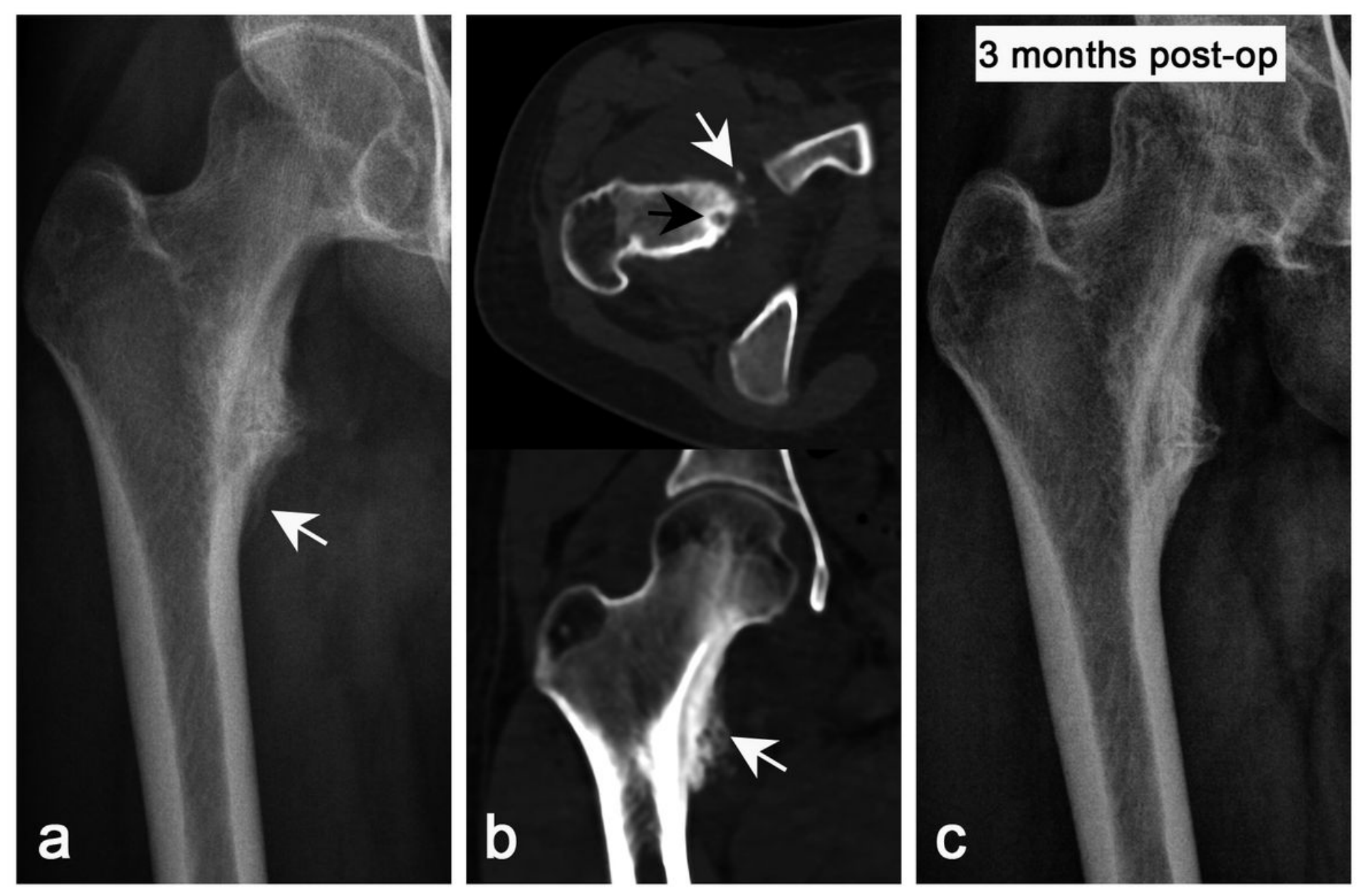

\section{Figure 3}

The preoperative and postoperative imaging characteristics of 00 in a lesser trochanter. (a) The radiography shows the periosteal reaction caused by the nidus but the nidus is not visible. (b) Thin-layer CT accurately displays the nidus and the surrounding hyperplastic bone. (c) Postoperative radiographs show that the reaction bone was completely absorbed and the bone morphology was restored to normal.

\section{Supplementary Files}

This is a list of supplementary files associated with this preprint. Click to download.

- SupplementalTable.doc 